\title{
Effect of Vinyl and Silicon Monomers on Mechanical and Degradation Properties of Bio-Degradable Jute-Biopol ${ }^{\circledR}$ Composite
}

\author{
M. A. KHAN, ${ }^{*}$ C. KOPP AND G. HINRICHSEN \\ Institute of Non-Metallic Materials \\ Technical University of Berlin, Polymer Physics \\ Englische Str. 20, D-10587, Berlin, Germany
}

\begin{abstract}
Composites of jute fabrics (Hessian cloth) and Biopol ${ }^{\circledR}$ were prepared by compression molding process. Three types of Biopol ${ }^{\circledR}$ (3-hydroxbutyrate-co3-hydroxyvalarate) such as D300G, D400G and D600G, depending on the concentration of 3-hydroxyvalarate (3HV) in 3-hydroxbutyrate (3HB) were taken for this purpose. Mechanical properties such as tensile strength (TS), bending strength (BS), elongation at break (Eb) and impact strength (IS) of the jute-Biopol ${ }^{\circledR}$ composites were studied. It was found that the composite with D400G produced higher mechanical properties in comparison to the other two types of Biopol ${ }^{\circledR}$. To increase mechanical properties as well as interfacial adhesion between fiber and matrix, 2-ethyl hydroxy acrylate (EHA), vinyl tri-methoxy silane (VMS) and 3-methacryloxypropyl tri-methoxy silane (MPS) were taken as coupling agents. Enhanced mechanical properties of the composites were obtained by using these coupling agents. Biopol ${ }^{\circledR}$ D400G composites showed the highest mechanical properties. Among the coupling agents EHA depicts the highest increase of mechanical properties such as tensile strength (80\%), bending strength (81\%), elongation at break (33\%) and impact strength (130\%) compared pure Biopol. SEM investigations demonstrate that the coupling agents improve the interfacial adhesion between fiber and matrix. The surface of the silanized jute was characterized by FTIR and found the deposition of silane on jute fiber was observed. Soil degradation test proved that the composite prepared with EHA treated jute exhibits better degradation properties in comparison to pure Biopol ${ }^{\circledR}$.
\end{abstract}

KEY WORDS: composite, biodegradable, jute, silane, Biopol ${ }^{\circledR}$.

*Author to whom correspondence should be addressed at Radiation and Polymer Chemistry Laboratory, Institute of Nuclear Science and Technology, Bangladesh Atomic Energy Commission, P.O. Box 3787, Dhaka, Bangladesh. E-mail: makhan@bangla.net 


\section{INTRODUCTION}

N RECENT YEARS a great interest has been generated in the use of renewable resource materials, e.g., natural fibers as reinforcing filler in thermoplastic composites, because increasing environmental consciousness and demands of legislative authorities, manufacture, use and removal of traditional composite structures usually made of glass carbon and aramide fibers embedded in epoxy, phonemic, polyurethane or unsaturated polyester resins are considered more critically. One important disadvantage of such composites is the fact that they are not biodegradable. Natural fiber composites reveal well mechanical properties combined with low density. The high level of moisture absorption by natural fibers, their poor wettability, and the insufficient adhesion between untreated fibers and the polymeric matrix can lead to debonding with age [1-3]. The main component of the natural fiber is cellulose. Jute contains $64 \mathrm{wt} \%$ cellulose [4] and anhydro- $d$ glucose is the main elementary unit of cellulose macromolecules, which contain three hydroxyl groups per glucose rings. These hydroxyl groups $(\mathrm{OH})$ form intramolecular hydrogen bonds with other glucose rings as well as with $\mathrm{OH}$ groups from the moisture. Therefore, natural fibers are hydrophilic in nature and their moisture content can reach $12.6 \%$ [5,6]. Composites of hydrophilic fiber with hydrophobic or nonpolar polymer matrix result in poor mechanical properties compared to pure polymer [7]. This is generally attributed to the lack of sufficient adhesion between natural fiber and polymer [8]. To improve the adhesion the surface of the fiber can be modified by chemical or physical methods. The most important chemical method of modification of the fiber surface is the chemical coupling method. The coupling agents used hereby contain chemical groups where one group can react with the fiber and the other one with the polymer. The bonds are covalent and hydrogen bonds as well as they improve the interfacial adhesion [9]. Silane coupling agents may contribute hydrophilic properties to the interface, especially when amino-functional silanes such as epoxies and urethanes silanes are used as primers for reactive polymers. The primers may supply much more amine functionality than can possibly react with the resin or polymer matrix in the interface. These amines which could not react are hydrophilic and are, therefore, responsible for the poor water resistance of the bonds $[10,11]$. Jute Biopol ${ }^{\circledR}$ composites were prepared with chemically modified jute fibers; alkali treated jute produced better mechanical properties as compared to other treatments such as cyanoethylation or grafting of monomers [12,13]. Khan et al. [14] prepared jute-Biopol ${ }^{\circledR}$ composites with higher tensile strength and bending strength by using silane coupling agents. Some acrylic monomers like 2-ethylhexyl acrylate (EHA) and 2-hydroxyethyl methacrylate (HEMA) were found to act as effective coupling agents for increasing the mechanical properties of jute-plastic composites, prepared under radiation techniques [15-17]. The present paper deals with the preparation of biodegradable composites with hessian cloth (jute fabrics) and dif- 
ferent types of Biopols ${ }^{\circledR}$ by compression molding using coupling agents and reports on mechanical and properties as well as the biodegradation of these composites.

\section{EXPERIMENTAL}

\section{Materials}

Three types of Biopol ${ }^{\circledR}$ poly [3 hydroxy butyrate (HB)-co-3 hydroxy valerate $(\mathrm{HV})$ ] depending on the concentration of 3 hydroxy valerate in 3 hydroxy butyrate like $\mathrm{D}_{300 \mathrm{G}^{\circledR}} \mathrm{P}(3 \mathrm{HB}-c o-5 \% 3 \mathrm{HV})$; $\mathrm{D} 400^{\circledR} \mathrm{P}(3 \mathrm{HB}-c o-8 \% 3 \mathrm{HV})$ and $\mathrm{D} 600^{\circledR}$ $\mathrm{P}(3 \mathrm{HB}-\mathrm{co}-10 \% 3 \mathrm{HV})$ were purchased from ICI Zeneca UK. Some properties of these Biopol ${ }^{\circledR}$ are shown in Table 1. 2-Ethyl hexylacrylate (EHA, structure I) and catalyst dicumyl peroxide were obtained from Merck Germany; vinyl trimethoxy silane (VMS, structure II) and 3-methacryloxypropyl trimethoxy silane (MPS, structure III) were received from Lancaster and Aldrich Co. Germany. Jute fabrics (hessian cloth) was collected from Bangladesh Jute Research Institute (BJRI), Dhaka, Bangladesh.

\section{Chemical Structure of Coupling Agents}

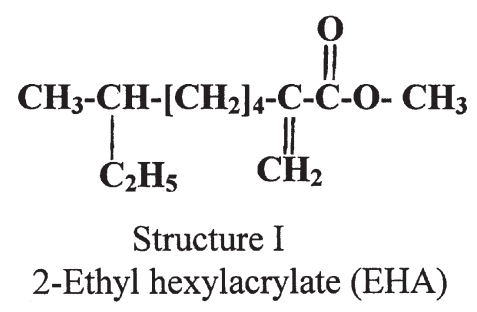

Table 1. Selected physical and mechanical properties of different types of Biopol ${ }^{\circledR}$.

\begin{tabular}{lccc}
\hline & \multicolumn{3}{c}{ Biopol $^{\circledR}$} \\
\cline { 2 - 4 } Properties & D300G $^{\circledR}$ & D400G $^{\circledR}$ & D600G $^{\circledR}$ \\
\hline Co-monomer $(3 \mathrm{HV})$ content (\%) & 5 & 8 & 10 \\
Melting point $\left({ }^{\circ} \mathrm{C}\right)$ & 162 & 153 & 144 \\
Tensile strength (MPa) & 31 & 28 & 23 \\
Elongation at break (\%) & 8 & 15 & 35 \\
\hline
\end{tabular}




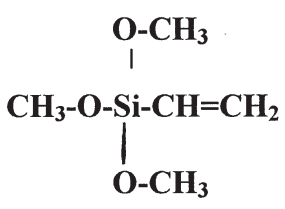

Structure II

Vinyl trimethoxy silane (VMS)

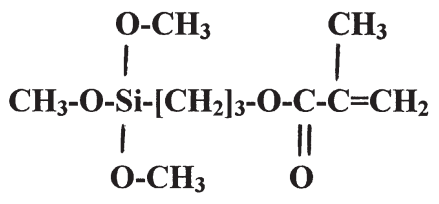

Structure III

3-Methacryloxypropyl trimethoxy silane (MPS)

\section{Method}

Hessian cloth was cut into desired size and heated at $105^{\circ} \mathrm{C}$ for 4 hours to remove the moisture from the jute. The hessian cloths were then soaked in a solution of $3 \%$ EHA and 1\% dicumyl peroxide in methanol for 5 minutes. Then the samples were dried in an ambient temperature. For silane treatment, preheated jute fabric was soaked in solution of $0.5 \%$ VMA and 2\% MPS in methanol for 5 minutes; $1 \%$ dicumyl peroxide was added to the solution. The fixed $\mathrm{pH}$ of the solution was maintained by adding $3 \%$ acetic acid. The treated jute fabrics were then dried at ambient temperature.

\section{Preparation of Composite}

Composites of Biopol ${ }^{\circledR}$ and hessian cloth were prepared by sandwiching two layers of hessian cloth in between three layers of Biopol ${ }^{\circledR}$ film of $1 \mathrm{~mm}$ thickness so that one layer of hessian cloth was placed in between two layers of Biopol ${ }^{\circledR}$ sheet. The prepreg was prepared by heating the jute-Biopol ${ }^{\circledR}$ at $160^{\circ} \mathrm{C}$ for 5 minutes under 2 tons $/ \mathrm{cm}^{2}$ in a heat-press. The prepreg materials were cooled to room temperature, cut to required size, placed in a mould and then heated again for 6 minutes at $160^{\circ} \mathrm{C}$ under a pressure 5 tons $/ \mathrm{cm}^{2}$.

The tensile properties of the neat Biopols ${ }^{\circledR}$ and their composites were determined using an Instron testing machine (model 1026). The tensile strength (TS) measurement and three point bending test were carried out following DIN 53455 and DIN 53452 standard methods respectively; impact strength was carried out by an impact tester (Zwick, Germany), using DIN 53433. All the results were taken as the average value of 5 samples.

\section{Fourier Transform Infrared Spectroscopy (FTIR)}

Both silanized and untreated jute fibers were analyzed by FTIR spectroscopy (Perkin Elmer, model Spectrum 2000) using Attenuated Total Reflectance (ATR) technique. 


\section{Scanning Electron Microscopy (SEM)}

The scanning electron micrographs of the samples were taken in an XL 20 Philips SEM. The tensile fracture surface of the composite samples was studied with the microscope operated at $20 \mathrm{kV}$. The samples were coated with a $10 \mathrm{~nm}$ layer of gold.

\section{Composting Degradation}

A uniform, reproducible compost mixture consisting of synthetic municipal solid waste (ED 73) with an initial moisture content of $63 \%$ related to dry mass and initial $\mathrm{pH}=7.2$ provided by the Federal Institute of Materials Research and Testing (BAM, Berlin) was used as degradation medium to measure the weight loss in a burial test (DIN 53739). Composite samples and Biopol ${ }^{\circledR}$ sheets of $25 \times 10 \times 2$ $\mathrm{mm}^{3}$ size were buried at a depth of $4 \mathrm{~cm}$. Samples were washed in distilled water and dried at $105^{\circ} \mathrm{C}$ in an oven for $24 \mathrm{~h}$ and then stored in a dissector. The weight of each sample was recorded before and after degradation.

\section{RESULTS AND DISCUSSION}

Three types of jute reinforced composites were prepared with three types of Biopol $^{\circledR}$; jute content in the composite was about $25 \%$. The mechanical properties of the composites such as tensile strength (TS), bending strength (BS), impact strength (IS) and elongation at break (Eb) were studied. To compare these properties with their respective Biopol ${ }^{\circledR}$ sheets of neat Biopol ${ }^{\circledR}(2 \mathrm{~mm}$ thickness $)$ were prepared in an analogous way and were taken as reference. The increased mechanical properties as a result of reinforcing jute has been expressed by factors, e.g., TS factor (Tf); BS factor (Bf); IS factor (If) and Eb factor (Ef). The tensile strength factor, Tf, was defined as the ratio of the TS of the composite (TSc) to that of pure Biopol $^{\circledR}$ sheets $(\mathrm{TSb}$ ), i.e., Tf $=\mathrm{TSc} / \mathrm{TSb}$. Similarly, Bf $=\mathrm{BSc} / \mathrm{BSb}$; IS $=\mathrm{ISc} / \mathrm{ISb}$ and $\mathrm{Ebc} / \mathrm{Ebb}$. The mechanical property factors of the composites are presented in Figure 1. Composite of Biopol ${ }^{\circledR}$ D 400G showed the highest values Tf (1.50), Bf (1.52) and If (2.0). Pure poly hydroxy butyrate (PHB) is a polymer with a high degree of crystallinity [18], where the degree of crystallinity of Biopol ${ }^{\circledR}$ is lower than that of PHB. The degree of crystallinity of copolymers of HB and HV is found to decrease with increase of HV in Biopol ${ }^{\circledR}$ [19]. The incorporation of fibers in Biopol may affect both crystallization kinetics and crystallinity of PHBV during the composite fabrication. The crystallinity of PHB and its copolymers with hydroxy valerate has an important influence on their mechanical properties. Biopol $^{\circledR}$ D400G contains $8 \%$ HV and the crystallinity reaches such a degree, which may be better for the mechanical properties of jute-composites than that of other Biopols ${ }^{\circledR}$. Elongation at break Ef of three types of composites is found less 


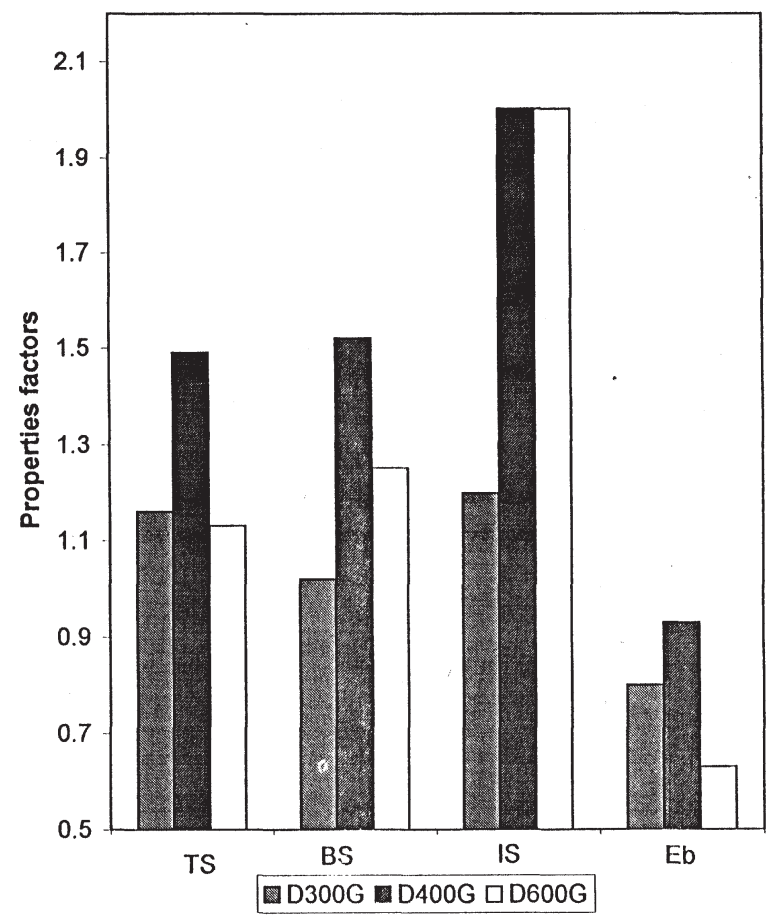

Figure 1. Tensile strength (TS), bending strength (BS), impact strength (IS) and elongation at break factors of Jute-Biopol ${ }^{\circledR}$ composites.

than unity; the rigidity of the composite increases as a result of reinforcement of fiber in $\mathrm{Biopol}^{\circledR}$ and reduces the elongation.

\section{Effect of Silane Monomer}

Two types of silicon monomers (VMS and MPS) were used to modify the jute surface to improve the interfacial adhesion between jute fiber and Biopol ${ }^{\circledR}$ matrix. Alkoxy silanes (structure IV) undergo hydrolysis, condensation and bond formation stage under base and acid catalysis. In addition to these reactions of silanol (structure V) with hydroxyls of fiber surface, the formation of polysiloxane structure can also occur [10].

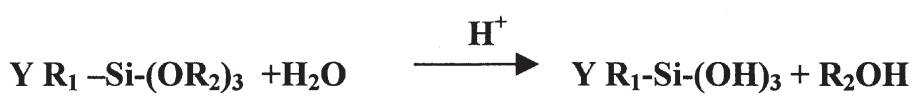


Very slowly, the silanetriol will be condensed to structure VI.

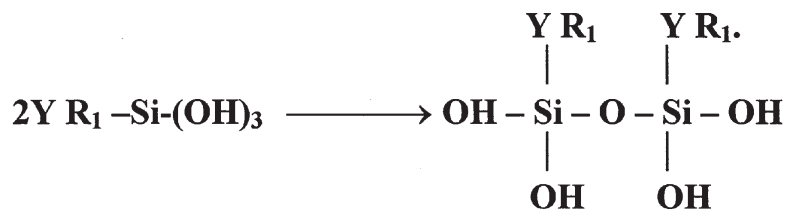

\section{Structure VI}

Further condensation will produce polysiloxane (structure VII) that is increasingly insoluble in water [20].<smiles>[R12][Si]([R1])(O)O[Si]([Y10])(O)O[Si]([R1])([R12])O[Si]([R12])(C)O</smiles>

\section{Structure VII ( Polysiloxane)}

The hydrolyzed silanol $\left[-\mathrm{Si}(\mathrm{OH})_{3}\right]$ reacts with hydroxyl group of cellulose and forms strong covalent bonds or hydrogen bonds.

\section{Characterization of Silanized Jute by FTIR}

To study the chemical reaction between silane (MPS) and the cellulose backbone of jute fiber both untreated and silanized jute fabrics were characterized by FTIR using Attenuated Total Reflectance (ATR) technique. The spectra of treated with MPS (HCMPS) and untreated fabrics (HC) are shown in Figure 2a for spectra $4000-700 \mathrm{~cm}^{-1}$ and in Figure $2 \mathrm{~b}$ for spectra $1500-700 \mathrm{~cm}^{-1}$. It is observed that some new absorption bands appear in the HCMPS curve. The absorption band at around $766 \mathrm{~cm}^{-1}$ can be attributed to the $-\mathrm{Si}-\mathrm{C}-$ stretching bond [21]. A very weak peak is observed at around $847 \mathrm{~cm}^{-1}$ which also corresponds to $\mathrm{Si}-\mathrm{C}$ bonds [22]. The broad peak from 925 to $1105 \mathrm{~cm}^{-1}$ could be attributed to the presence of asymmetric stretching of $-\mathrm{Si}-\mathrm{O}-\mathrm{Si}$ or $\mathrm{Si}-\mathrm{O}-\mathrm{C}\left(1014-1090 \mathrm{~cm}^{-1}\right)$ bonds $[22,23]$. The absorption bands for $-\mathrm{Si}-\mathrm{O}-\mathrm{Si}$ are indicative of the existence of polysiloxanes (structure VII) deposited on the jute fiber and of $\mathrm{Si}-\mathrm{O}-\mathrm{C}$ confirming the occurrence of a condensation reaction between jute fiber and coupling agent (MPS) [21]. A prominent absorption is also observed at around $1200 \mathrm{~cm}^{-1}$ which corresponds to $\mathrm{Si}-\mathrm{O}-\mathrm{C}$ bonds [21]. 


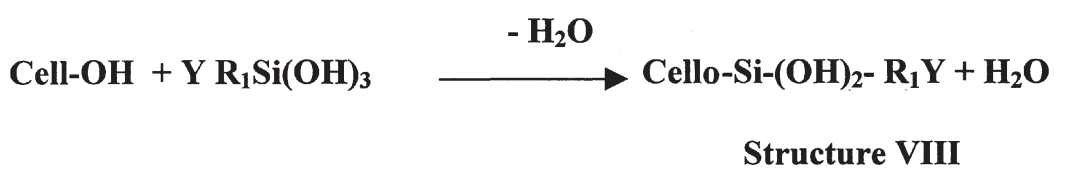

Condensation reaction

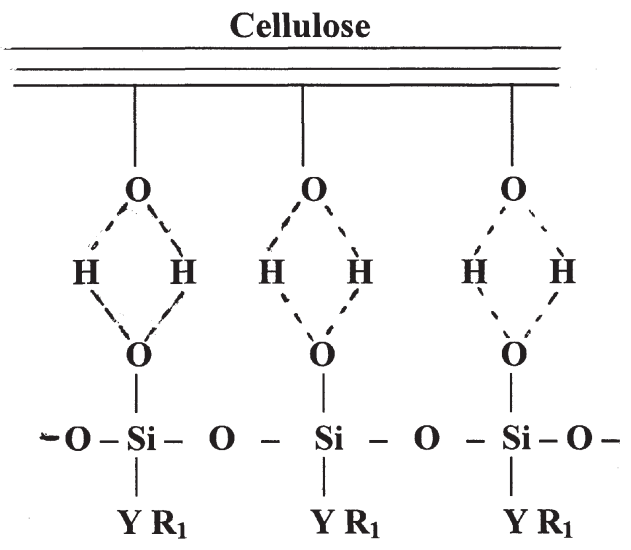

Hydrogen bonding
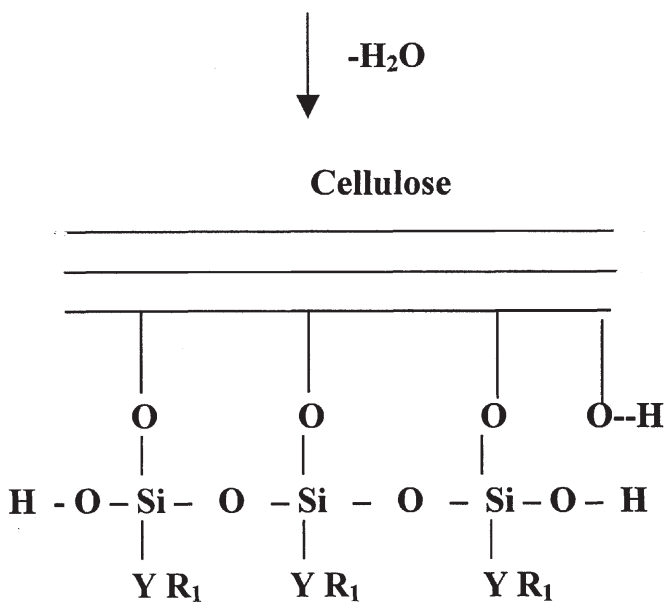

Structure VIII 


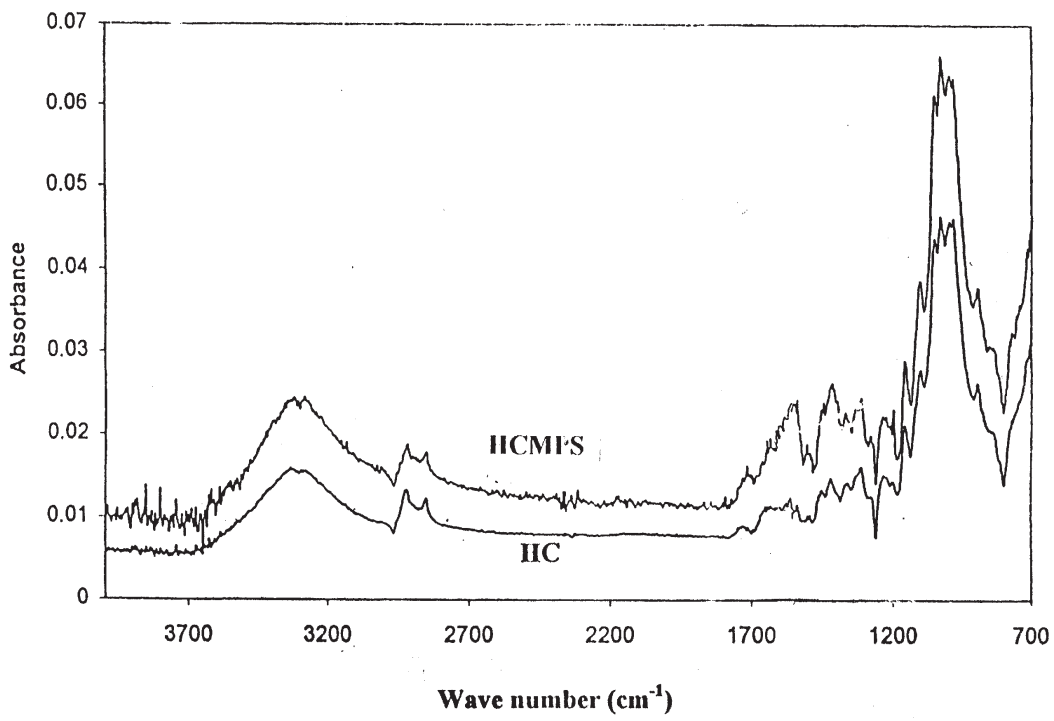

Figure 2a. IR spectra of untreated hessian cloth (HC) and silanized hessian cloth (HCMPS) from $4000-700 \mathrm{~cm}^{-1}$.

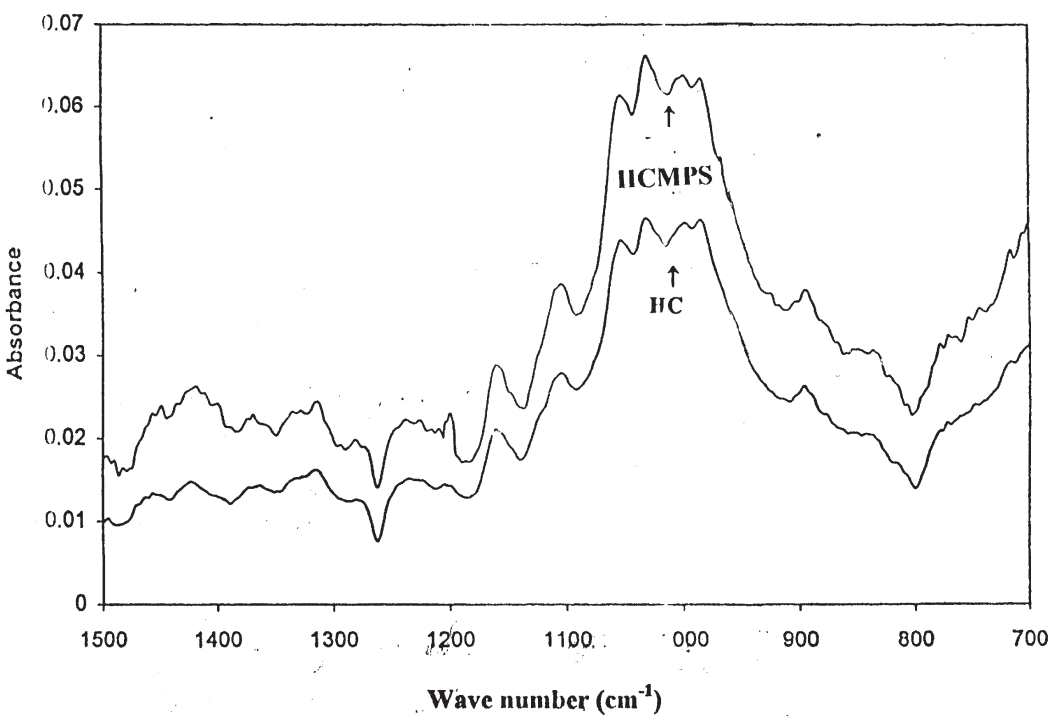

Figure $\mathbf{2 b}$. IR spectra of untreated hessian cloth $(\mathrm{HC})$ and silanized hessian cloth (HCMPS) from $1700-700 \mathrm{~cm}^{-1}$ 


\section{Effect of Silanes on Mechanical Properties}

The tensile properties of the composites prepared with VMS and MAPS treated jute fabrics are plotted in Figures 3 and 4 respectively. By using these two silanes the mechanical properties of the composites of the three Biopol ${ }^{\circledR}$ types produced higher mechanical properties. Among the Biopols ${ }^{\circledR}, \mathrm{D} 400 \mathrm{G}^{\circledR}$ showed higher mechanical properties when prepared with VMS and MPS. This is due to the stronger interfacial bonds between Biopols and jute fiber through the functional groups of silane monomers. Hydroxyl $(-\mathrm{OH})$ groups of cellulose of jute undergo condensation reaction with silanol of hydrolyzed silane, and other functional groups (vinyl groups) of silane may react with Biopol ${ }^{\circledR}$ through graft copolymerization reaction with the help of the thermal initiator dicumyl peroxide during composite fabrication. The silanized jute highly reduces its moisture regain capacity. On the

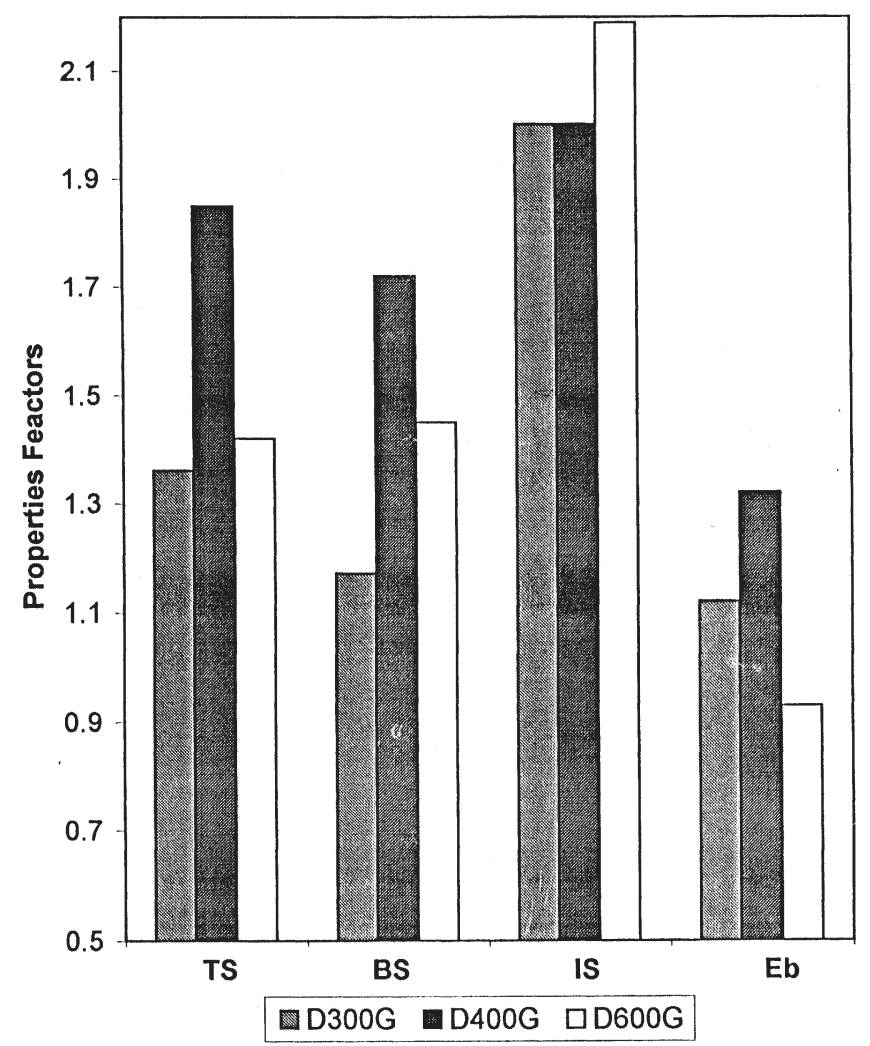

Figure 3. Tensile strength (TS), bending strength (BS), impact strength (IS) and elongation at break factors of VMS treated Jute-Biopol ${ }^{\circledR}$ composites. 


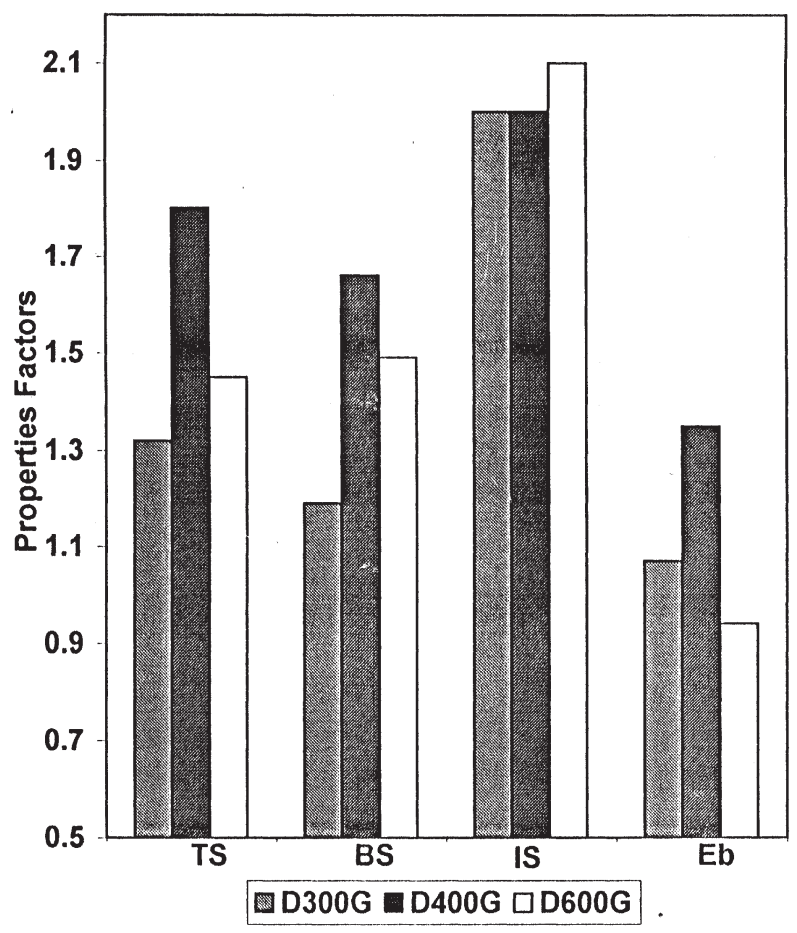

Figure 4. Tensile strength (TS), bending strength (BS), impact strength (IS) and elongation at break factors of MPS treated Jute-Biopol ${ }^{\circledR}$ composites.

other hand, untreated jute induces poor wettability and adhesion characteristics with Bipol matrix while the presence of moisture at the jute-Biopol interface promotes the existence of voids at the interface due to the hydrophilic nature of jute. Because of the moisture and voids at the interface the adhesion weakens and produces composites with lower strength and stiffness.

\section{Effect of EHA}

In addition, the effect of EHA on the performance of mechanical properties of jute-Bipol ${ }^{\circledR}$ composites was studied and the results are shown in Figure 5. It was found that all mechanical properties were increased significantly. The tensile strength increases about 80 and 31\% and bending strength 81 and 29\% respectively as compared to pure Bipol and untreated jute composite, in the case of D400G. The elongation at break of EHA treated jute composite was observed to increase about $30 \%$ in comparison to pure Biopol and about $40 \%$ in comparison in comparison to the composite of untreated fiber. 


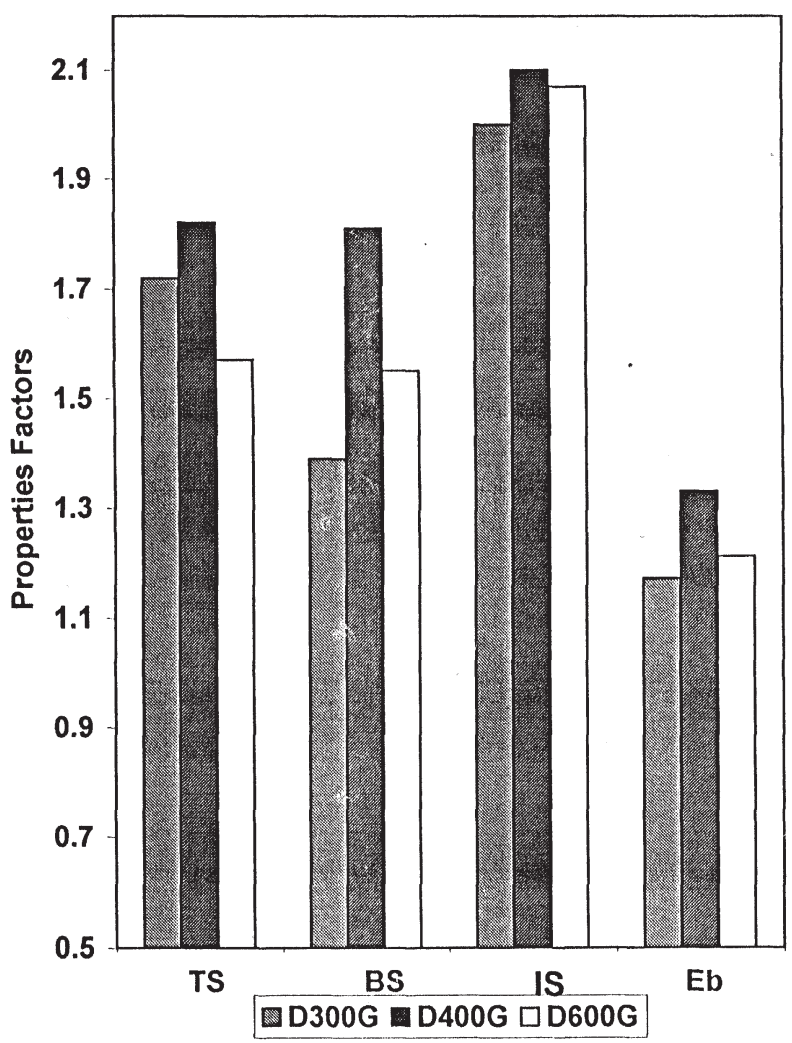

Figure 5. Tensile strength (TS), bending strength (BS), impact strength (IS) and elongation at break factors of EHA treated Jute-Biopol ${ }^{\circledR}$ composites.

The superior mechanical properties of EHA treated fabrics may be attributed to the fact that EHA improves the adhesive characteristics of the fiber by producing a rough surface topography. Thus, the development of a rough surface topography and the enhancement of the fiber aspect ratio offer a better fiber-matrix interface adhesion and an increase in mechanical properties.

In addition, the vinyl group of the acrylate moiety of EHA reacts with $\mathrm{OH}$ groups of the cellulose backbone of jute fiber through by graft-copolymerization. As a result, the hydrophilic nature of jute is reduced, which increases the effective surface area available for contact with the matrix polymer.

\section{Interfacial Properties}

Interfacial properties of Biopol-jute composites are investigated by scanning 
electron microscopy of tensile fracture surfaces. Figure 6 demonstrates the fracture surfaces of untreated and different type surface modified jute composites. SEM observations indicate that there is considerable difference in the fibre-matrix interaction between treated and untreated jute composites. The improved bonding is observed for surface modified jute composites compared to their unmodified counter parts. Although we observe in both cases fibre pull out phenomena, in case of the surface modified composites a considerable amount of matrix polymer residue remains on the fibre. In case of untreated jute composite [Figure 6(a)] fiber pull-out in bundle form is observed whereas in case of EHA modified sample [Figure 6(b)], agglomeration of fibres into bundle form is comparatively prevented indicating better interaction than in the previous system. Similarly, the micrographs of MPS [Figure 6(c)] and VMS [Figure 6(d)] modified jute composites also show improved fibre-matrix interaction as observed from the reduction of fibre pull-out and good dispersion of fibres into the matrix system, thereby producing micropores at the interface [24].

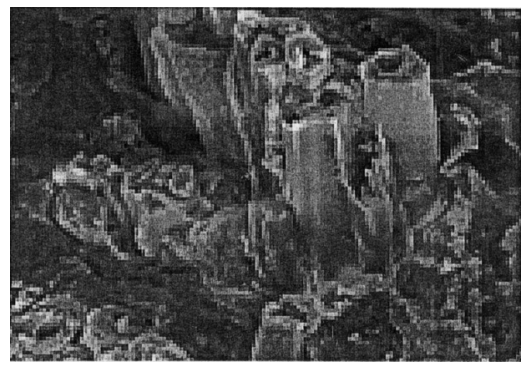

(a)

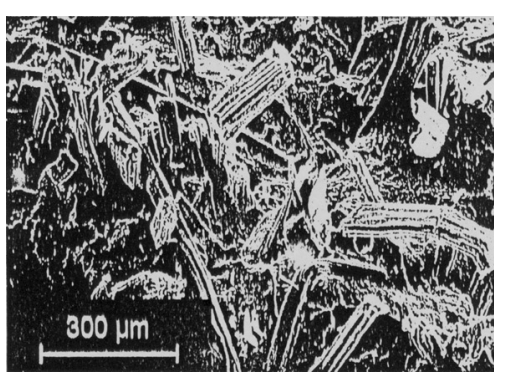

(c)

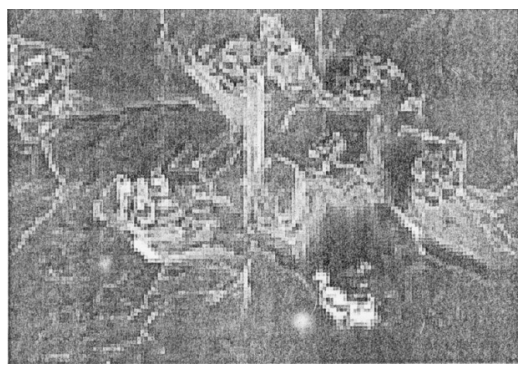

(b)

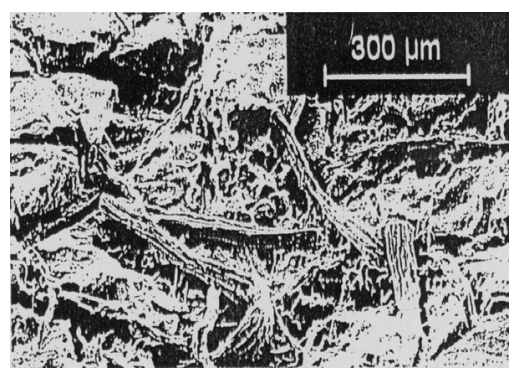

(d)

Figure 6. SEM photographs of different composites. Jute-Biopol ${ }^{\circledR}$ composite (a); VMS treated Jute-Biopo ${ }^{\circledR}$ composites, (b) MPS treated Jute-Biopol ${ }^{\circledR}$ composites, (c) EHA treated Jute-Biopol ${ }^{\circledR}$ composites. 


\section{Degradation of Composites}

The soil degradation studies of biocomposites are important so far as the aim and scope of such work is concerned. Besides the measurements of mechanical properties, studies of compost degradation of composites of treated and untreated jute are also carried out in detail. Three types of Biopol $®$ were taken for soil degradation as reference. Soil degradation data are tabulated in Table 2. Biopol ${ }^{\circledR}$ D-600G showed the highest weight loss over other Biopols ${ }^{\circledR}$, which may be due to the influence of crystallinity. All composites prepared with both untreated and treated jute showed higher degradation rates than that of their respective neat Biopol $^{\circledR}$. For better understanding, the weight loss of the degradation results of Biopol ${ }^{\circledR}$ D-400G and its composites are plotted in Figure (7) which represent the weight loss verus degradation time. The initial (up to 30 days) rate of degradation of all composites is more or less same. Then, higher degradation rate of untreated jute composite was observed which reaches more than $50 \%$ weight loss within 90 days. The change of degradation rate was found to be higher in composites of EHA

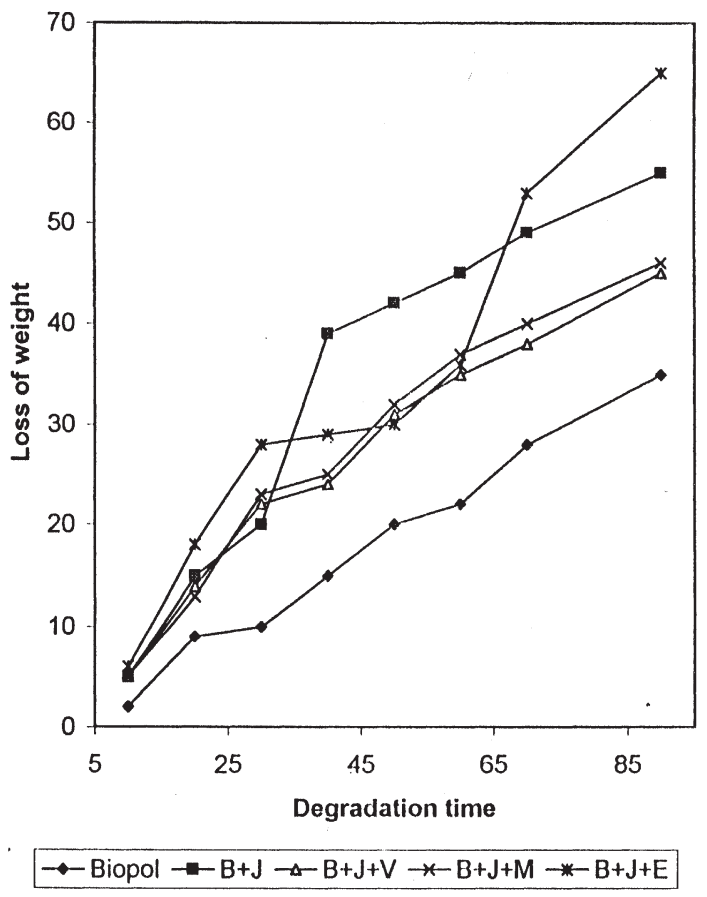

Figure 7. Weight loss of Biopo/ ${ }^{\circledR} D 400 G$ and its composites independence degradation time. 
Table 2. Weight loss of Biopol ${ }^{\circledR}$ and their composites as a result of composting degradation.

\begin{tabular}{|c|c|c|c|c|c|c|c|c|c|c|c|c|c|c|c|}
\hline \multirow{3}{*}{$\begin{array}{l}\text { Degradation } \\
\text { Time (days) }\end{array}$} & \multicolumn{15}{|c|}{ Weight Loss (\%) } \\
\hline & \multicolumn{5}{|c|}{ D-300G } & \multicolumn{5}{|c|}{$D-400 G$} & \multicolumn{5}{|c|}{ D-600G } \\
\hline & B & BJ & BJV & BJM & BJE & B & BJ & BJV & BJM & BJE & B & BJ & BJV & BJM & BJE \\
\hline 10 & 2 & 4 & 3 & 3 & 5 & 2 & 5 & 5 & 5 & 6 & 2 & 5 & 3 & 4 & 4 \\
\hline 20 & 5 & 10 & 9 & 10 & 14 & 9 & 15 & 14 & 13 & 18 & 9 & 18 & 12 & 19 & 24 \\
\hline 30 & 9 & 18 & 16 & 17 & 25 & 10 & 20 & 22 & 23 & 28 & 18 & 30 & 17 & 18 & 36 \\
\hline 40 & 12 & 32 & 20 & 21 & 27 & 15 & 39 & 24 & 25 & 29 & 18 & 38 & 21 & 26 & 43 \\
\hline 50 & 16 & 40 & 25 & 25 & 29 & 20 & 42 & 31 & 32 & 30 & 19 & 42 & 22 & 30 & 47 \\
\hline 60 & 20 & 50 & 30 & 31 & 32 & 22 & 45 & 35 & 37 & 36 & 30 & 45 & 42 & 40 & 58 \\
\hline 70 & 28 & 56 & 33 & 35 & 52 & 28 & 49 & 38 & 40 & 53 & 39 & 63 & 50 & 53 & 66 \\
\hline 90 & 34 & 63 & 41 & 42 & 63 & 35 & 55 & 45 & 46 & 65 & 45 & 70 & 60 & 64 & 79 \\
\hline
\end{tabular}

B $=$ Biopol ${ }^{\circledR} ; \mathrm{BJ}=$ Jute + Biopol $^{\circledR}$ Composite; BJV $=$ Biopol ${ }^{\circledR}+$ Jute + VMS Composite; BJM $=$ Biopol ${ }^{\circledR}+$ Jute + MPS Composite; BJE $=$ Biopol ${ }^{\circledR}+$ Jute + EHA Composite. 
treated jute after 60 days and reached the highest weight loss (65\%) within a sample after a biodegradation period of 90 days. Composites of VMS and MPS treated jute showed minimum weight loss (less than 50\%) which may be due to the non-biodegradability of the silane.

\section{ACKNOWLEDGEMENTS}

M. A. K. is greatful to Alexander von Humboldt Foundation for his AvH Fellowship.

\section{REFERENCES}

1. Gassan, J. and A. K. Bledzki. 1993. Angew. Makromol. Chem., 236: 129.

2. Maldas, D., B. V. Kokta, R. G. Raj and C. Daneault. 1998. Polymer, 29: 1255.

3. Zadorecki P. and P. Flodin. 1986. J. Appl. Polym. Sci., 31: 1699.

4. Gassan, J. and A. K. Bledzki. 1995. 7th Intern. Tech. Textile Symp., Frankfurt (Germany), June 19-21.

5. Ugbolue, S. C. O. 1990. Text. Inst., 20(4): 1.

6. Kucharyou, M. S. 1993. Tekst. Prom., 8-9: 23.

7. Maldas, D. and B. V. Kokta. 1993. Comp. Interf., 1: 87.

8. Kokta, B. V. and D. Maldas. 1998. International Wood and Natural Fiber Composites Symposium, Kassel (Germany), June 29-30.

9. Gassan, J. and A. K. Bledzki. 1997. Proceedings of ICCM-11, Gold Coast, Australia, Vol. IV, Composites Processing and Microstructure, July 14-18.

10. Mital, K. L. 1992. Silanes and Other Coupling Agents, VPS, BV, The Netherlands.

11. Bledzki, A. K., S. Reihmane and J. Gassan. 1996. J. Appl. Polym. Sci., 59: 1329.

12. Mohanty, A. K., M. A. Khan, S. Sahoo and G. Hinrichsen. 2000. J. Mater. Sci. (In press).

13. Mohanty, A. K., M. A. Khan and G. Hinrichsen. 2000. Compos. Sci. Technol. (In press).

14. Khan, M. A., K. M. I. Ali, G. Hinrichsen, C. Kopp and C. Koepke. 1999. Polym.-Plast. Technol. Eng., 38(1): 99.

15. Ali, K. M. I., M. A. Khan and K. S. Akhunzada. 1999. J. Appl. Polym. Sci., 77: 641.

16. Ali, M. A., M. A. Khan, K. M. I. Ali and G. Hinrichsen. 1998. J. Appl. Polym. Sci. $70: 843$.

17. Khan, M. A., O. M. Ali, K. M. I. Ali. 1999. Adv. Polym. Technol., (In press).

18. Barham, P. K., A. Keller, E. L. Ohun and P. A. Holmes. 1984. J. Mater. Sci., 19: 2781.

19. Bloembergen, S. D., A. Holden, G. K. Hamer, T. L. Bluhm and R. H. Marchessault. 1986. Macromolecules, 19: 2865.

20. Berger, S. E. 1987. “Organo-functional Silane," in Handbook of Filler for Plastics, Ed. H. S. Katz and J. V. Mile Wski, Van Nostrand Reinhold Co. Inc.

21. Ishida, H. and J. Koeing. 1976. 31st Ann. Tech. Conf. Reinf. Plast. Compos. Inst., The Society of Plastics Industry Inc., Section 6-c.

22. Briteher, L., D. Kehoe, J. Matisons and G. Swincer. 1995. Macromolecules, 28: 3110.

23. Pouehert, C. J. (Ed.), The Aldrich Library of Infrared Spectra, 3rd Ed., 62, 123, 1535.

24. Dong, S., S. Sapieha and H. P. Schrieber. 1993. Polym. Eng. Sci., 33: 343. 